\title{
Crecimiento de colonia y halo de hidrólisis celulolítico de las bacterias termófilas GCB-13 y GCC-13 a diferentes temperaturas
}

\section{Colony growth and cellulolytic hydrolysis halo of thermophilic bacteria GCB-13 and GCB-13 at different temperatures}

${ }^{1}$ Daladier Castillo Cotrina

${ }^{2}$ Freddy Ninaja Zegarra

${ }^{3}$ Roberto Castellanos Cabrera
ORCID: 0000-0003-0133-5921

ORCID: 0000-0002-8720-5222

ORCID: 0000-0003-0133-5921

\section{RESUMEN}

El trabajo tuvo como objetivo determinar el diámetro de colonia con su halo celulolítico de las bacterias termófilas GCB-13 y GCC-13 a diferentes temperaturas. Las bacterias fueron reactivadas en caldo $\mathrm{CMC}$ e incubadas a $50{ }^{\circ} \mathrm{C}$ por $48 \mathrm{~h}$, luego sembradas por puntura en el medio agar CMC contenido en placas Petri por triplicado para cada temperatura a la que fue incubado $\left(35,40,45,50,55\right.$ y $\left.60{ }^{\circ} \mathrm{C}\right)$ durante 48 horas. El diámetro de las colonias con sus halos celulolíticos se obtuvo con ayuda de una regla milimetrada. El halo de hidrólisis fue obtenido restando el diámetro de la colonia del diámetro de la colonia con halo celulolítico. Los diámetros máximos $(\mathrm{mm})$ obtenidos de colonia y de halo celulolítico, respectivamente, fueron para la bacteria GCB-13 9,17 a $45^{\circ} \mathrm{C}$ y 6,42 a $55^{\circ} \mathrm{C}$, y para la bacteria GCC-13 10,33 a $45^{\circ} \mathrm{C}$ y 7,33 a $50{ }^{\circ} \mathrm{C}$.

Palabras claves: Celulolítico, cepas termófilas, crecimiento, halo de hidrólisis.

\begin{abstract}
The objective of the work was to determine the colony diameter with its cellulolytic halo of the thermophilic bacteria GCB-13 and GCC-13 at different temperatures. The bacteria were reactivated in $\mathrm{CMC}$ broth and incubated at $50^{\circ} \mathrm{C}$ for 48 hours, then punctured onto the $\mathrm{CMC}$ agar medium contained in Petri dishes in triplicate for each temperature at which it was incubated $\left(35,40,45,50,55\right.$ and $\left.60^{\circ} \mathrm{C}\right)$ for 48 hours. The diameter of the colonies with their cellulolytic halos was obtained with the help of a millimeter ruler. The hydrolysis halo was obtained by subtracting the diameter of the colony from the diameter of the cellulolytic halo colony. The maximum diameters $(\mathrm{mm})$ obtained from the colony and the cellulolytic halo, respectively, were for the bacterium GCB-13 9,17 at $45^{\circ} \mathrm{C}$ and 6,42 at $55^{\circ} \mathrm{C}$, for the bacterium GCC-13 10,33 at $45^{\circ} \mathrm{C}$ and 7,33 at $50^{\circ} \mathrm{C}$.
\end{abstract}

Keywords: Cellulolytic, thermophilic strains, growth, hydrolysis halo.

\footnotetext{
${ }^{1}$ Universidad Nacional Jorge Basadre Grohmann. Escuela Académica Profesional de Biología y Microbiología. Tacna, Perú. E-mail: dcastilloc@unjbg.edu.pe

${ }^{2}$ Universidad Nacional Jorge Basadre Grohmann. Escuela Académica Profesional de Biología y Microbiología. Tacna, Perú. E-mail: freddyelbiologo@gmail.com

${ }^{3}$ Universidad Nacional Jorge Basadre Grohmann. Escuela Académica Profesional de Biología y Microbiología. Tacna, Perú. E-mail: rcastellanosc@unjbg.edu.pe
} 


\section{INTRODUCCIÓN}

Las biomasas que más abundan en la Tierra son la celulosa y la hemicelulosa por lo que constituyen el potencial para dar solución a las demandas energéticas como ambientales de bioenergía (Sánchez \& Cardona, 2008). Los organismos celulolíticos tienen una naturaleza ubicua. Los hongos como las bacterias son utilizados bastante por sus cualidades para producir una gran gama de celulasas y hemicelulasas. Las bacterias presentan ventajas sobre los hongos en algunos aspectos; suelen tener una mayor tasa de crecimiento que permite una producción más rápida de enzimas recombinantes (Maki et al., 2009).

La degradación de la celulosa requiere la ayuda de ácidos o de enzimas para convertirla a azúcares más simples. A través de los años la degradación biológica de la celulosa utilizando enzimas celulolíticas provenientes de hongos y bacterias ha sido ampliamente estudiada (Tomme et al., 1995). Las enzimas celulolíticas llamadas celulasas permiten la bioconversión de material lignocelulósico, su obtención es importante (Alam et al., 2009). Esto constituye un nuevo enfoque biotecnológico para la biodegradación de biosólidos junto a la producción de enzimas industriales que muestran el beneficio de presentar costos muy bajos y es amigable con el medio ambiente (Alam et al., 2003; Kaur et al., 2017).

Las enzimas celulolíticas pueden ser producidas por bacterias termófilas (Zapata y Castellanos, 2014; Hasnaa et al., 2018). Las bacterias celulolíticas, como las termófilas en condiciones favorables, en medios sólidos con celulosa crecen y se desarrollan formando colonias y produciendo las celulasas que se reconocen por el halo de hidrólisis de celulosa que se forma alrededor de las colonias (Guzmán et al., 2015). El crecimiento y desarrollo de las bacterias está afectado por varios factores, entre ellos por la temperatura (Baraybar y Monje, 2017). Algunos microorganismos capaces de producir celulasas son las bacterias del género Clostridium, Bacteroides, Erwinia, Acetovibrio, Microbispora y Streptomyces (Ballesteros et al., 2008).

El trabajo tuvo como objetivo determinar el diámetro de colonia con su halo celulolítico de las bacterias termófilas GCB-13 y GCC-13 a diferentes temperaturas.

\section{MATERIAL Y MÉTODOS}

Las bacterias celulolíticas GCB-13 y GCC-13 fueron aisladas de los géiseres de Candarave, Tacna, Perú y donadas para el presente trabajo por el Laboratorio de Biotecnología enzimática de la Facultad de Ciencias de la Universidad Nacional Jorge Basadre Grohman. Estas bacterias fueron reactivadas en caldo CMC e incubadas a 50 ${ }^{\circ} \mathrm{C}$ por 48 horas.

De las suspensiones bacterianas obtenidas, de cada una, se sembró inóculos por puntura sobre la superficie y en el centro del medio agar CMC contenido en placas Petri, por triplicado, para cada temperatura las cuales luego fueron incubadas $(35,40,45,50,55 \mathrm{y}$ $\left.60^{\circ} \mathrm{C}\right)$.

La composición del medio de cultivo CMC (g/ml) fue: Carboximetilcelulosa 10,0; extracto de levadura 2,5; Peptona universal 2,5; Sulfato de amonio 0,5; Cloruro de calcio 0,5; Fosfato monobásico de potasio 0,1; Fosfato dibásico de potasio 0,1; Agar-agar 15,0; pH 7 (Gaitán, 2007). 
Se midieron los diámetros de las colonias y sus halos celulolíticos con ayuda de una regla milimetrada (Constantino et al., 2011; Ortiz y Uribe, 2010). El diámetro del halo de hidrólisis se determinó restando el diámetro de colonia del diámetro de la colonia con su halo celulolítico.

Para determinar el mayor diámetro de colonia y el mayor halo celulolítico para cada bacteria se hizo uso del análisis de varianza y de la prueba de Tukey.

\section{RESULTADOS}

En la Tabla 1 y en la Figura 1, se muestran el mayor diámetro de colonia 9,17 mm a 45 ${ }^{\circ} \mathrm{C}$ y el mayor halo celulolítico $6,42 \mathrm{~mm}$ a $55^{\circ} \mathrm{C}$ obtenido en la bacteria GCB-13.

\section{Tabla 1}

Diámetro promedio $(\mathrm{mm})$ de colonia, halo más colonia y halo celulolítico de la bacteria GCB13 incubada a diferentes temperaturas

\begin{tabular}{lcccccc}
\hline Temperatura & $\mathbf{3 5}{ }^{\circ} \mathbf{C}$ & $\mathbf{4 0}^{\circ} \mathbf{C}$ & $\mathbf{4 5}^{\circ} \mathbf{C}$ & $\mathbf{5 0}^{\circ} \mathbf{C}$ & $\mathbf{5 5}^{\circ} \mathbf{C}$ & $\mathbf{6 0}^{\circ} \mathbf{C}$ \\
\hline Colonia & 1.83 & 2.00 & 9.17 & 5.33 & 4.92 & 0.00 \\
\hline Halo + colonia & 1.83 & 2.00 & 14.00 & 11.17 & 11.33 & 0.00 \\
\hline Halo sólo & 0.00 & 0.00 & 4.83 & 5.83 & 6.42 & 0.00 \\
\hline
\end{tabular}

\section{Figura 1}

Diámetro promedio ( $\mathrm{mm}$ ) de colonia y de halo celulolítico de la bacteria GCB-13 incubada a diferentes temperaturas

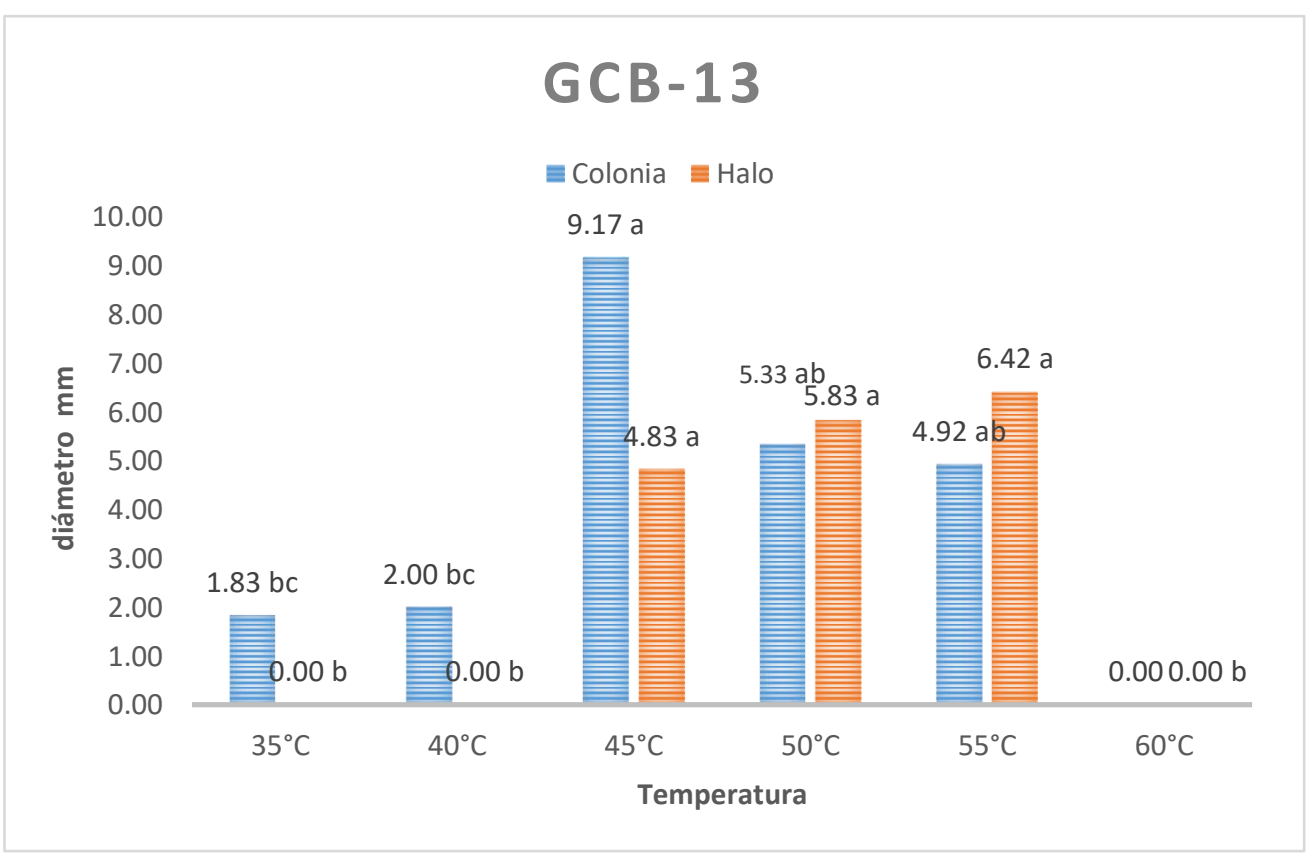

En la Tabla 2 y Figura 2, se muestra el mayor diámetro de colonia $10,33 \mathrm{~mm}$ a $45^{\circ} \mathrm{C}$ y el mayor halo celulolítico $7,33 \mathrm{~mm}$ a $50{ }^{\circ} \mathrm{C}$ obtenido en la bacteria GCC-13. 


\section{Tabla 2}

Diámetro promedio $(\mathrm{mm})$ de colonia, colonia con halo celulolítico y halo celulolítico obtenido en la bacteria GCC-13 a diferentes temperaturas

\begin{tabular}{lcccccc}
\hline Temperatura & $\mathbf{3 5}^{\circ} \mathbf{C}$ & $\mathbf{4 0}^{\circ} \mathbf{C}$ & $\mathbf{4 5}^{\circ} \mathbf{C}$ & $\mathbf{5 0}^{\circ} \mathbf{C}$ & $\mathbf{5 5}^{\circ} \mathbf{C}$ & $\mathbf{6 0}^{\circ} \mathbf{C}$ \\
\hline Colonia & 0.00 & 0.00 & 10.33 & 6.33 & 5.50 & 2.50 \\
\hline Halo + colonia & 0.00 & 0.00 & 15.67 & 13.67 & 11.58 & 3.17 \\
\hline Halo sólo & 0.00 & 0.00 & 5.33 & 7.33 & 6.08 & 0.67 \\
\hline
\end{tabular}

\section{Figura 2}

Diámetro promedio ( $\mathrm{mm}$ ) de colonia y de halo celulolítico de la bacteria GCC-13 a diferentes temperaturas

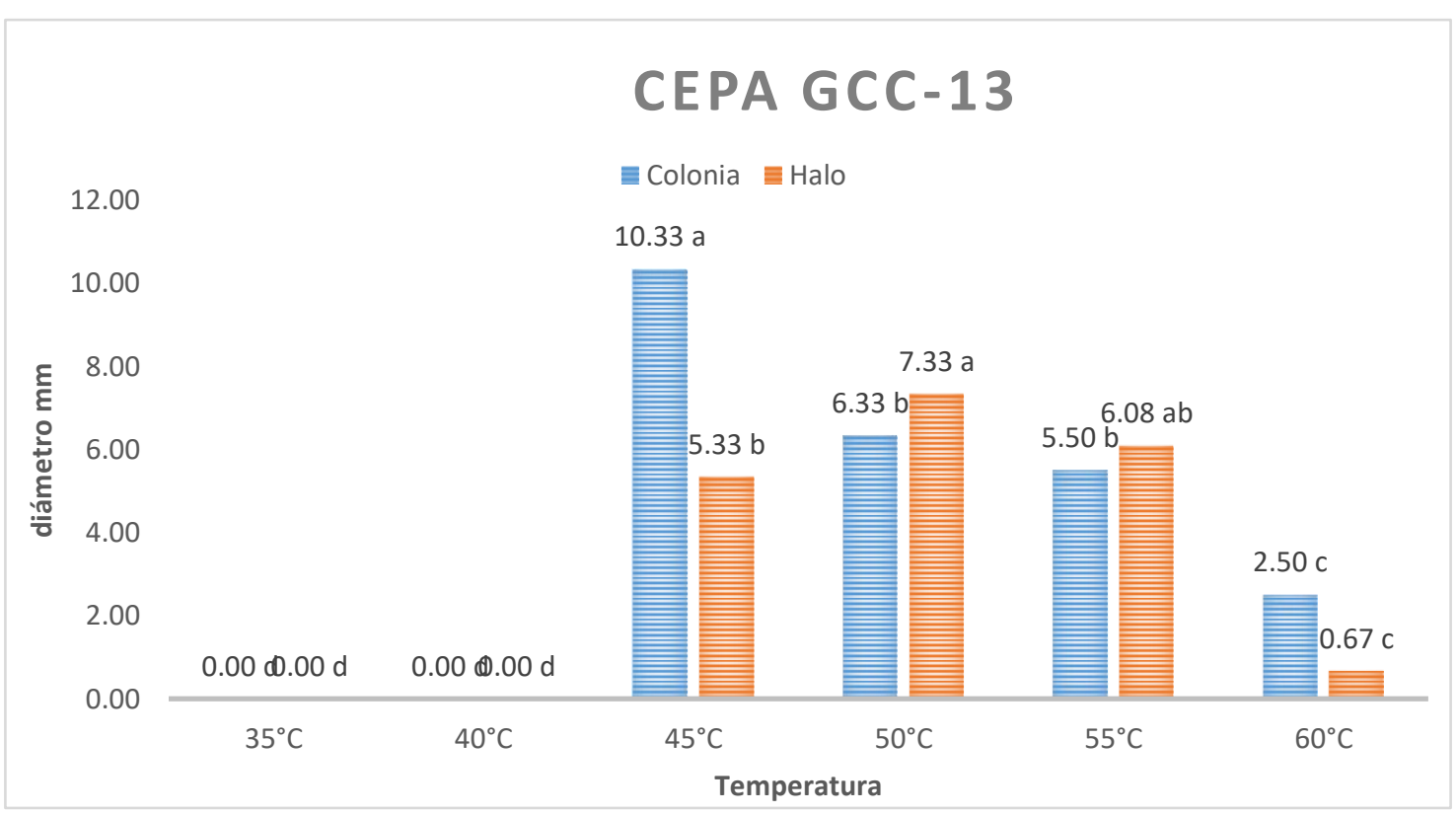

\section{DISCUSIÓN}

En las bacterias GCB-13 como GCC-13, el mayor crecimiento de sus colonias como de sus respectivos halos celulolíticos está en función de una temperatura óptima. La colonia de la bacteria GCB-13 tuvo el máximo crecimiento de $9.17 \mathrm{~mm}$ a $45^{\circ} \mathrm{C}$; la $\mathrm{GCC}-13$, $10.33 \mathrm{~mm}$ a $45^{\circ} \mathrm{C}$. En relación a los halos celulolíticos, la bacteria GCB-13 tuvo el máximo halo, $6.42 \mathrm{~mm}$ a $55^{\circ} \mathrm{C}$; mientras que la GCC-13 tuvo $7.33 \mathrm{~mm}$ a $50{ }^{\circ} \mathrm{C}$. Esto confirma que la temperatura es un factor importante en el crecimiento y desarrollo de los microorganismos. Cada microorganismo tiene su temperatura óptima, ya sea para su crecimiento como para otras características (Anwar et al., 2014; Guzmán et al., 2015; Tamariz, 2014).

El máximo diámetro de colonia obtenido a determinada temperatura para cada una de las bacterias indica que una mayor producción de biomasa se puede conseguir incubando la bacteria a la temperatura en la cual se obtuvo el máximo diámetro de colonia. Esto es 
importante cuando se desea obtener biomasa como inoculante entre otras aplicaciones (Guzmán et al., 2015).

El máximo diámetro de halo celulolítico obtenido en la GCB-13 como en la GCC-13 son diámetros significativos comparados a los reportados por otros autores. La bacteria AO19, parte de un conjunto de microbios evaluados, dio el mayor halo de hidrólisis celulolítico de 12,33 mm (este diámetro no resta el diámetro de la colonia) (Guzmán et al., 2015). La cepa B1R, parte de varias bacterias termófilas evaluadas, formó el mayor halo de hidrólisis de $10 \mathrm{~mm}$ (Zapata y Castellanos, 2014).

\section{CONCLUSIONES}

El mayor diámetro de colonia para la bacteria GCB-13 fue de $9,17 \mathrm{~mm}$ a $45^{\circ} \mathrm{C}$; y para la GCC-13 fue de $10,33 \mathrm{~mm}$ a $45^{\circ} \mathrm{C}$.

El mayor halo celulolítico para la bacteria $\mathrm{GCB}-13$ fue de $6.42 \mathrm{~mm}$ a $55{ }^{\circ} \mathrm{C}$; y para la GCC-13 fue de $7,33 \mathrm{~mm}$ a $50{ }^{\circ} \mathrm{C}$.

Para una misma bacteria, la temperatura óptima para su máximo diámetro de colonia es independiente de la temperatura óptima para su máximo halo celulolítico.

\section{REFERENCIAS}

Alam, M. Z.; Mansor, M. F. \& Jalal, K.C.A. (2009) Optimization of decolorization of methylene blue by lignin peroxidase enzyme produced from sewage sludge with Phanerochaete Chrysosporium. J Hazardous Mater, 162: 708-15.

Alam, M.Z.; Razi, A.F. \& Molla, A.H. (2003). Biosolids accumulation and biodegradation of domestic wastewater treatment plant sludge by developed liquid state bioconversion process using a batch fermentor. Water Res, 37: 3569-78.

Anwar, Z.; Gulfraz, M. \& Irshad, M. (2014). Agro-industrial lignocellulosic biomass a key to unlock the future bio-energy: A brief review. Journal of Radiation Research and Applied Sciences, 7(2), 163-173.

Ballesteros, I.; Ballesteros, M.; Manzanares, P.; Negro, M.; Olova, J. \& Saez, F. (2008). Dilute Sulfuric acid pretreatment of Cardoon for ethanol production. Biochemical Engineering Jounal, 84-91.

Baraybar, A. y Monje, C. (2017). Obtención de celulasas de Trichoderma sp. a partir de orujo de uva para producir bioetanol usando hojas de mazorca de maíz (tesis de pregrado). Universidad Católica de Santa María. Arequipa, Perú.

Constantino, M.; Gómez, R.; Álvarez, J.; Pat, J. \& Espín, E. (2011). Efecto de la inoculación de Azotobacter chroococcum y Glomus intraradices en el crecimiento y nutrición de plántulas de papaya en fase de vivero. Agron. Costarricense, 35, $15-31$.

Guzmán, A.; Zambrano, D.; Rivera, R.; Rondón, A.; Laurencio, M. y Pérez, M. (2015). Aislamiento y selección de bacterias autóctonas de Manabí-Ecuador con actividad celulolítica. Cuba. Cultivos Tropicales, 36(1), 7-16.

Hasnaa R. Temsaah; Ahmed F. Azmy; Mai Raslan; Amr E. Ahmed \& Walaa G. Hozayen. (2018). Isolation and Characterization of Thermophilic Enzymes Producing Microorganisms for Potential Therapeutic and Industrial Use. J Pure Appl Microbiol, 12(4), 1687-1702. 
Kaur, Ajit; Surekha Bathia \& Urmila Gupta Phutela. (2017). Partial purification and characterizacion of cellulolytic enzimes extracted from Trichoderma reesei inoculated digested biogas slurry. India. Journal of pure and applied Microbiology, 11 (4), 1953-1963.

Maki, M; Leung KT \& Qin W. (2009). The prospects of cellulase-producing bacteria for the bioconversion of lignocellulosic biomass. Int. J. Biol. Sci., 5: 500-516.

Ortiz, M. y Uribe, D. (2010). Determinación de la actividad lignocelulolítica en sustrato natural de aislamientos fúngicos obtenidos de sabana de pastoreo y de bosque secundario de sabana inundable tropical. Cienc. Suelo, 28, 169-180.

Sánchez, ÓJ \& Cardona, CA. (2008). Trends in biotechnological production of fuel ethanol from different feedstocks. Bioresour. Technol., 99:5270-5295.

Tamariz, C. (2014). Diversidad de bacterias termotolerantes celuloliticas y xilanolíticas aisladas de fuentes termales del Callejón de Huaylas (tesis doctoral). Universidad Nacional Mayor de San Marcos. Lima, Perú.

Tomme, P.; Warren, R.A. \& Gilkes, N.R. (1995). "Cellulose hydrolysis by bacteria and fungi". Advances in Microbial Physiology, 37(1): 1-81.

Zapata, H. y Castellanos, R. (2014). Aislamiento e identificación de bacterias celuloliticas termófilos de géiseres naturales de Candarave - Tacna. Ciencia \& desarrollo (Tacna), 18:29-36. 